ZalǫcZnIil

\title{
COMPARATIVE ANALYSIS OF MEDIA. THE TRANSFORMATION OF RELATIONS BETWEEN SCRIPT AND IMAGE - FROM ANALOGUE MEDIA TO INTERACTIVE ENVIRONMENT
}

AGNIESZKA SMAGA

\begin{abstract}
Wydział Nauk Humanistycznych UKSW
Faculty of Humanities, Cardinal Stefan Wyszyński University in Warsaw

a.smaga@uksw.edu.pl
\end{abstract}

The subject of this comparative analysis is digital imagery and the interplay of script and image within it ${ }^{1}$. These two media are characterised, on the one hand, by a degree of autonomy and different orders of expression (basic elements, methods of binding them), while on the other hand they remain related in terms of similarity and, sporadically, identity. Script and image are treated both as heterogeneous (selectively different) and heteronomous (mutually acting on each other) forms. Therefore, not the finally produced media, but the relationships between them were placed at the centre of the study (Kasperski, 2010: 65-68), as in mathematical category theory ${ }^{2}$.

The specific dependencies of the digital word and image have been described in detail primarily by Jay David Bolter (2001) and Mike Sandbothe (2000). The analyses of these researchers are an important point of reference for this article. Sandbothe acknowledged that forms of communication in the digital hypertext environment that have been separate up to now are changing their specific characteristics and entering into new

1 This article does not discuss the sound aspect of the digital medium.

2 Reasoning in the order of category is distanced from set theory. A collection and its elements cease to be fundamental, autonomous concepts, and move to the background. Heteronomous transformations and interference of the given media are most important. 
arrangements - four digital entanglements: the scriptualisation of speech, the oralisation of writing, the iconisation of script and the scriptualisation of image (Sandbothe, 2000: 217-222). The specified transformations would accentuate the transmedial nature of web pages, where heterogeneous mediums of communication would form an amalgamation of the system, an integrative whole at the level of semiotics and semantics. The subject of this comparative analysis is the relation between script and image, which is why attention has been focused on the last two transmedial processes ${ }^{3}$.

Sandbothe, guided by researcher's intuition, suggested that there is a mechanism common to both media (words and images) that emerges from the pragmatic level, i.e. the functioning of a message. He did not analyse this process, he only suggested its communicative effects, which are based primarily on the introduction of words and images into motion, and binding these media to reality, not only symbolically to its reference, but factually to the real reference, which takes place at the moment of clicking or touching a digital sign (Sandbothe, 2000: 218-219).

Logical reasoning demands that a common mechanism for the functioning of images and words online can be achieved only with the contribution of

3 According to Sandbothe, the iconisation of phonetic script is based on treating text as an image structure in terms of its delivery, and thus its reception. Another manifestation of the process of the iconisation of script was the rehabilitation of non-phonetic scripts (pictograms, ideograms). The researcher found that in the digital environment icons function as further elements of 'pictorial script' and their sequences are becoming an appropriate language of digital communication (Zawojski, 1999: 40-41). The next interference between media identified by Sandbothe was the scriptualisation of the digital image. The author understood it as 'detachment' of the image from the function of imitating reality. An icon, like script, appears in this case as an auto-reference, referring to itself. This means that we 'read' it as a linguistic model, that is, from letter to letter, from word to word, from sentence to sentence, and not as an image by reference to real or unreal non-artistic reality. This process is carried out in graphics programs through 'edit' operations of an image, the same as script, such as changes and deletions. Sandbothe pointed out that digital raster images have these properties due to their technological determinants. However, he did not present the same characteristics in the context of vector graphics, although they are primarily subject to these change procedures, of which there are definitely more than the two mentioned above. 
convergent technology that generates them, further made available at the presentation level. Each of the three levels of digital communication was introduced by one and the same medium (perhaps because of this we should call it a transmedium?), namely, applied graphics, which, as a unified form of transmission, refers only to the presentation layer. On a fundamental level, every digital message is reduced to a numerical representation (Manovich, 2002: 27).

The identification of script and icon signs, which Sandbothe wrote about, rarely occurs at the actual presentation level, because it is not related to an attempt to build a simple relationship of their visual identity. Therefore, it is not subject to processes known from analogue culture. The two transpositions highlighted by the researcher - the iconisation of script and the scriptualisation of image - are not the result of the interdependence of these two categories, rather they are the effect of the overriding action of the trans-mechanism - the graphic code. One should, therefore, speak more about graphicalisation, which introduces the proper procedures for processing both media. This graphical editing constructs the interactions between digital writing and image. The features of flat design constitute to a varying degree the properties of both analogue and digital messages 4 . In the case of the latter, they construct the specificity of presentation and communication in this environment ${ }^{5}$. They introduce multilevel, variable interactions between semiotically varied medial categories.

Graphic code is a variant of an iconic code. That is why the level at which a message is generated is important, i.e. the physical structure of

${ }^{4}$ In research about print media (books, newspapers and other media), graphic media has generally been omitted, because it was 'not seen' or treated as transparent and therefore unimportant. The exception are studies by Philip Meggs (1998), Lewis Blackwell and David Carson (2000).

${ }^{5}$ Graphic mode is understood online as a way of operating an external device, such as a monitor or a printer. In this mode, individual pixels are processed, that is, the individual elements that make up an image on a monitor screen (also in a computer memory). This strategy allows maps, charts, drawings, photographs, films and animations to be processed. The alternative to graphic mode is alphanumeric text - fast in action, but does not support pixels. It defines a method of working in which only characters of a specified code (such as ASCII) are available. 
the substrate, the properties of the tools and the operational and design mechanisms, selected from a broad range of possibilities. Online graphics are an even more complex and complicated service that defines the process of generating, presenting and manipulating scripts, images and sounds. Graphical procedures derive directly from the specifics of mechanical, digital recording of distinct types of data. They take place in the form of zeros and ones stored on a computer's hard disc in the form of bits. This form of notation allows information to be duplicated without loss of quality and to be processed with mathematical algorithms, then graphical rules. Also, TCP/IP-compliant web-based data transmission involves the continuous recovery and processing of encoded characters, and their reproduction regardless of where they are located in space and time.

These mechanisms, which are characteristic of the online environment, shape the tools, procedures, and conventions of digital design. Graphic operations include both single characters and groups of them, as well as page space and finally web space. They have a creative, crafted character ${ }^{6}$ and therefore refer back to the practice of using tools. The choice of graphical instrument for processing material is dictated by the way it is used by the user. For example, edits made in the future on a website can be made using tools such as layers or stacks, selections, paths, shapes, channels, styles, colours, filters, masks, brushes, pencils, sprays, softeners, erasers, scissors, knives, pipettes, paint buckets, calligraphy, shadows, frames, contour pens and many others! With certain programs (Adobe Photoshop, Adobe Illustrator, CorelDRAW, GIMP and others), words and images can be modified and composed in many ways. They are subjected to editorial processes (Sandbothe treats this as one of the forms of scriptualising images), which rarely take place based on text operations only (replacement and deletion in linear form), but more often on the basis of strict graphic editing: reduction, enlargement, duplication, addition, substraction, merging, averaging, transformation (rotation, reversing), scaling, blocking, grouping, hiding and merging layers, filling, framing, metamorphosing, marking (here there is a whole range of possibilities), etc. Saving in digital form allows not

6 'No longer an Analytical Engine, suitable only for crunching numbers, it has become Jacquard's loom - a media synthesizer and manipulator' (Manovich, 2002: 26). 
only straightforward changes to be made, but also multiple units separated from one another to be combined. They are displayed as a heterogeneous whole, but stored in databases as separate, standalone components, so each of them can be individually modified, e.g. through layers, channels, paths and other functions. The variety of tools and operations is a significant determinant of graphic code.

Digitally and design-generated communication components are revealed to recipients through the graphical user interface of web pages and web browsers. The GUI defines a visual representation of information (writing, image and sound) by a computer and interactions with the user by 'drawing' using input (mouse, trackball, touchpad) and input/output (touch screen) devices and the use of controllers and widgets. As can be expected, websites are not static, rather they are dynamic, created on the fly by calling on information. They actually match the needs of their users. Thus, the design of images, sounds, texts and animations that constitute the content of web pages are strongly linked to databases - another relational category - with their indexing and economy of access and the emancipation of the user in terms of information (Belting, 2007: 49-54). This is why graphical editing departs from the convention imposed by paper and creates structures capable primarily of storing and combining many diffuse media. And the functionality of digital graphics is no longer determined by the semantic element, as in analogue design, where the text was treated as a model for describing actions or events, generating complex content that needed to be translated into graphical content, and thus performing its functions. Meanwhile, in the new media environment, design has become

'meta-design'. Today, the designer must create not only a graphic identity, but also information architecture, a navigation system and other structures that will be used by the customer as information carriers. In short, the graphic designer has become an interface designer. (Austin, Doust, 2008: 16-17)

Consequently, utility, alongside the digital recording structure, affects the graphical editing process of text and image. Graphics both build and follow the specifics of the digital environment. They introduce interferences that are themselves the result of interactions between the properties of the material described above, through techniques and choices as well as perceptual and user practices in culture. This produces a continuous 
editing, a dynamic process: on the one hand intermediation between diffuse messages, and on the other hand, hypermediation (Bolter, 2001: 39) - displaying the properties of transmediation. In this way, graphical editing moves from being a finite representation to function primarily as a design interface. As a result of this graphic editing, we get digital graphic presentations, not graphic-icons, but also graphic user interface for mobile, responsive applications and web pages. By the same token, applied graphics and digital communication, existing with its help, require a specific research procedure - one that does away with the search for analogue imaging and writing, image and text prototypes. The new cognitive approach is based on the specifics of digital communication as described above, built from a level of universal communication using a GUI - academic perception 'follows' the expectations and needs of the user of the message, through the perception of the message, to the generated semantics, and further semiotics. Real people are placed at the centre of research interest, as is the case with the design and production of GUI websites ${ }^{8}$. In this way we avoid the discrepancy that Susan

7 Flat design has always oscillated between these two alternatives, placing them closer to the second. From the level of presentation, the imaging it proposes, thanks to far advanced reduction in form, was characterised by a high degree of simplification, the procedure of transition from colour, lightening and formal variety to graphic simplicity. Digital graphics, due to their great diversity, even better reflect the paradox of transparency and opacity that is typical of our Western culture. The graphical interface can take two forms: from apparent transparencye.g. in games - to hypermedia, best seen in web interfaces, especially mobile and responsive interfaces (Weibel, 2008: 5-10).

8 The proposed research path is similar to the order in which websites are created. The first stage is the experience strategy (validation analysis, heuristic analysis, usability tests), then comes market research (targeting users, user profiles, and an interactive shopping map). Websites, before they reach the user, are evaluated for their user-friendliness. For this purpose, they are tested on focus groups, where the time required to perform a particular task is checked, characters seen first are analysed, as well as those that cause most difficulty when performing a task. It turns out that the assumptions of the customer and the designer do not always match the expectations of users. Graphic designers in the design of user-oriented interfaces - like researchers - are accompanied by philosophical thought, according to which design should expand the opportunities - perceptual, educational, 
Sontag talked of between the literal meaning of a message and the actual perception and needs of users. First, we ask 'how and what does graphic code do', and only later 'what does it say' (Sontag, 1966: 13). Then, the goal of comparative analysis can be both practical and theoretical. In the first case, it will help to identify and improve the user experience at the moment of interaction; in the second - it will be connected with the procedure of knowledge acquisition by the recipient. By providing the participant with a variety of tools and procedures for handling communications, the process of constructing meanings and signs is supported.

In practice, the user of a graphical interface of a system, application or web page oscillates between three alternative needs and expectations. The user has a desire to enter a seemingly real, non-mediated world (realistic picture, photography, animation, film). In this case, the user observes the entire range of effects that build the expected illusion of the medium's transparency: geometric perspective, colour, and air, shading, variable scales, colour saturation, and more. On the other hand, there is also a fascination with the possibilities offered by the graphical tools of mediation (personalisation, choice, interaction, linking, change selection, highlighting $)^{9}$. The user, seeing an opaque, graphical interface of a system, application (especially on a smartphone or iPad) or web page feels 'pleasure' in the beginning. Admiring the simplicity of the GUI, combined with the graphical attractiveness of the icons, the user stops understanding them as images that imitate reality. The user also does not read the characters as a text: continuously, linearly, cause-and-effect. He is only delighted by them. Quickly, however, his sight begins to wander, looking for the ability to decode the graphical elements of the GUI or web page content (leading to a specific functionality or tool). In this case, there is a third category of needs and expectations, i.e. practical, there are practical wants, such as finding information, buying, renting, sending, sharing, printing.

cognitive, decision-making and practical - of individuals and societies. Planning understood in this way affects human knowledge, behaviour and attitudes and makes changes within them.

9 'The interface is not a transparent window through which we observe computer data; on the contrary - it modifies it decisively' (Manovich, 2001: 65). 
The three variants of user contact with a message suggested above are available from the graphical interface. For interfaces of operating systems, applications and mobile and responsive web pages, the transition between the first two user needs and the orders of a message is increasingly less visible.

Signs that are initially transparent are eliminated. A blank contact icon can be filled with a photo of a real person. But do we do it? If yes, we take a photo, edit it, cut it to the shape of a square, a circle, a rectangle of a certain size and add it by hand. In this case, the graphic medium has made an enhanced hypermediation and offers an entire range of modification possibilities: from resolution to white balance, contrast, perspective, size, shape and other advanced edits. The interface 'assures' the user of their perfection, suggesting that it will be better than a real photograph, because it offers - by its modification - an introduction to the world that is shown.

However, opaque signs or hypermediating graphical elements, are displayed. In this case, the interface draws users' attention as a pure, constellation form. It stimulates their sense of interaction, combinatorics and creation. For example, the Windows smartphone operating system is built of two-dimensional, simplified, uniformly coloured tiles. The screen settings can be modified (background, leading colour) as well as the start-up screen, by entering pictures from the camera (made by the user or from the library) by selecting the pattern and number of tiles. The position of email, screen lock, internet sharing, application corner and much more can be adjusted. Further applications can be installed and with great satisfaction we can uninstall them if we want to increase operating and mass memory. The enormous variety of tools and associated functions can lead to a communication situation which will not lead to constructing messages referring - through their image or language nature - to the world beyond the interface, but rather they will focus on the modification of the interface itself $^{10}$. Theoretically, we may fall for the magic of the graphic transmedium. But will this actually happen?

10 The ability to manipulate an image with graphical editing pulls an image away from merely being a reflection of reality. An icon can itself become an alternative, virtual, abstract world. It is then treated in terms of technology, aesthetics, and function. 
For the user, an interface's transparency (linked to its image) or opacity (close to written text) is usually not important. Thus, also not important, as suggested at the outset, is the distinction between image and script. For digital communication users, what is more important is the fast and effective performance of tasks such as sending messages, finding specific information, buying, selling, renting, viewing photos, checking weather, bank accounts, shares, email etc. The functionality of an interface is linked, therefore, to a direct, even immediate, response from the recipient. The user's activity is thus a process of mediation occurring with the use of a flat design. Therefore, graphical editing introduces operations on image, text, sound and combinations of these, but not to illustrate, describe or structure meanings, but rather to effectively send and use them (fast, economically and errorfree). At the moment of clicking, or after a user asks a specific question, the multi-semiotic content is downloaded and displayed on the screen according to a previously designed image template. A graphical interface 'treats' script and image on the one hand as standalone units - stored separately in databases in a way that makes them quick and easy to find; on the other hand, it threats them heteronomously, mutually acting, reinforcing each other in the presentation and message. Graphical editing skilfully combines recipients' expectations about the message access: on the one hand in terms of precision (on the model of a script), on the other in terms of a constellation (according to the iconic prototype). It scales in this way two structures of reception, recognised in our culture as different ${ }^{11}$. The user functionality of a message is understood as accurate and synthetic mediation (economic, reductive), which results in analogous features present at the semantic and semiotic level, where the three levels of a message circulate in a feedback loop. In the digital environment, there is no 'implosion' of signifié, or domination and diversity of signifiant, since the correct form is conditioned by effective, mutual communication, creativity and above all usability. This surface explosion exposes the key, primary features of concepts at the expense of their secondary quality. For a GUI, the sign with the greatest value is the one that works fast and accurately, like an arrow fired into an archery target or a missile aimed at a bullseye.

${ }^{11}$ Bolter talks about the opposition of these two reception poetics (Bolter, 2001: 61-66). 
The integrated word-image order of an expression was already a feature of analogue graphics. The tension between the semantic raster, arising from writing, and that associated with image is eliminated from the level of reception. The process of reading and watching was difficult to separate from each other. In the digital version of the procedure, these are combined, and are actually subordinate to their practical application. The graphic conditioning of the digital message, in accordance with its specific application, 'forces' a utility order on text and image.

Mutual dependence at the user, semantic and semiotic levels will continue to evolve in the online environment, as users possess for the first time such an efficient interaction tool, and with it the power of co-operation, co-creation and sharing, which they will certainly not give up when visiting web pages, blogs, as well as in chats, video conferencing, games, simulations, etc. Users will spend more and more time, with increasing pleasure, in the digital world, which they will consume and co-create with the available tools and graphic procedures. Mutual influence between the level of presentation and use means that a visible space is imposed, combined with its destruction, onto the object used, such as a web page, enhancing the relationship between the form and the function of the message. As a result, a 'package' (signifiant) is created at the same time as a 'product' (signifié), which is a kind of means (technique) to stimulate user expectations (Weibel, 2008: 11-28). In the longer perspective, reading/viewing will firstly lead to a redesign of the current level of graphic presentation, including writing and image, and, secondly, it will also define the self-perception of the act of writing and imaging.

\section{Selected bibliography}

Tricia Austin, Richard Doust (2008), Projektowanie dla nowych mediów, trans. A. Garbiński, PWN, Warszawa.

Hans Belting (2007), Antropologia obrazu. Szkice do nauki o obrazie, trans. M. Bryl, Universitas, Kraków.

Jay David Bolter (2001), Writing Space: The Computer, Hypertext, and the Remediation of Print, Lawrence Erlbaum Associates, Mahwah.

Norbert Bolz (1997), Estetyka cyfrowa, trans. J. Ostaszewski, [in:] Pejzaże audiowizualne: telewizja, wideo, komputer, ed. by A. Gwóźdź, Universitas, Kraków. Nicolas Bourriaud (2012), Estetyka relacyjna, trans. Ł. Białkowski, Muzeum Sztuki Współczesnej MOCAK, Kraków. 
Max Bruinsma (2003), Deep Sites, Intelligent Innovation in Contemporary Web Design, Thames \& Hudson, London.

David Carson, Lewis Blackwell (2000), The Other End of Print: David Carson, Graphic Design, and the Aesthetics of Media, Laurens King Publishing, London.

Konrad Chmielecki (2010), Od estetyki intermedialności do estetyki transmedialności. Perspektywy refleksji nad sztuka w kontekście problematyki transgresji mediów i konwergencji kulturowej, [in:] Sztuka w przestrzeni transmedialnej, ed. Tomasz Załuski, Oficyna Drukarska Jacek Chmielecki, Łódź.

Vilém Flusser (2002), Writings, University of Minnesota Press, Minneapolis.

Elisa Giaccardi (2005), Metadesign as an Emergent Design Culture, "Leonardo" vol. 4.

Monika Górska-Olesińska (2009), Słowo w sieci. Elektroniczne dyskursy, Wydawnictwo Uniwersytetu Opolskiego, Opole.

Andrzej Hejmej (2013), Komparatystyka. Studia literackie - studia kulturowe, Universitas, Kraków.

Henry Jenkins (2006), Convergence Culture: Where Old and New Media Collide, New York University Press, New York - London.

Steven Johnson (1999), Interface Culture: How New Technology Transforms the Way We Create and Communicate, Basic Books, New York.

Edward Kasperski (2010), Kategorie komparatystyki, Wydawnictwo UW, Warszawa. Krzysztof Lenk (2011), Krótkie teksty o sztuce projektowania, słowo/obraz terytoria, Gdańsk.

Lev Manovich (2001), The Language of New Media, The MT Press Cambridge, London.

Philip B. Meggs (1998), A History o Graphic Design, Van Nostrand Reinhold, New York.

Richard Poulin (2012), Graphic Design and Architecture, a 20th Century History: A Guide to Type, Image, Symbol, and Visual Storytelling in the Modern World, Rockport Publishers, Beverly (Ma).

Mike Sandbothe (2000), Interactivity - Hypertextuality - Transversality. A MediaPhilosophical Analysis of the Internet, "Journal of Linguistics" vol. 24.

Susan Sontag (1966), 'Against Interpretation' and Other Essays, A Delta Book, New York. 
Peter Weibel (2008), From Data to Images and Back. An Introduction to the Visual Systems of Thorbjørn Lausten, [in:] MAGNET. Thorbjørn Lausten's Visual

Systems, ed. M. Søndergaard, P. Weibel, Kehrer Verlag, Heidelberg.

Widzieć/Wiedzieć, ed. by P. Dębowski, J. Mrowczyk (2011), Wydawnictwo Karakter, Kraków.

Wiek ekranów. Przestrzenie kultury widzenia, ed. by A. Gwoźdź i P. Zawojski (2002). Rabid, Kraków.

Piotr Zawojski (1999), Od obrazów pisma do pisma obrazów, [in:] Słowo w kulturze multimediów, ed. Zbigniew Suszyński, Instytut Filologii Polskiej UwB, Bialystok.

Piotr Zawojski (2012), Sztuka obrazu i obrazowania w epoce nowych mediów, Oficyna Naukowa, Warszawa.

\section{Digital sources}

Elisa Giaccardi Elisa, Gerhard Fisher, Meta-Design: A Framework for the Future of End-User Development, http://13d.cs.colorado.edu/ gerhard/papers/EUDmeta-design-online.pdf.

Piotr Zawojski, Interfejs - sztuka interfejsu - „Interface Culture”, http://www.zawojski. com/2014/04/21/interfejs-sztuka-interfejsu-interface-culture-2/\#more-432.

Piotr Zawojski, Obrazy elektroniczne - eksplozja produkcji, implozja sensu?, http://www.zawojski.com/2006/04/19/obrazy -elektroniczne-\%E2\%80\%93-eksplozja-produkcji-implozja-sensu/.

\section{Comparative Analysis of Media. The Transformation of Relations between Script and Image - from Analogue Media to Interactive Environment}

A digital communiqué operates with GUI not to depict, describe or structure the meanings but, above all, to transfer them. At the moment of clicking, that is, when a specific question is being asked by the user (customer), specific semiotically varied content is downloaded and displayed on the screen in accordance with the pre-designed, graphic template.

Thus, graphical interface treats writing and image on the one hand as heterogeneous units - stored in databases, in a way that makes them quick and easy to find; on the other hand - heteronomous, that is, affecting each other at the level of presentation and manipulation of the message. Graphical 
edition skillfully combines the expectations of recipients concerning the access to the message: on the one hand - precise (along the lines of the language), on the other - economic, reducing (iconic), and it merges in this way two structures of reception, considered in our culture to be different.

Pragmatic functionality of digital message is understood as accurate and synthetic mediation, which results in further analogous features from the level of semiotics and semantics, where the highlighted three planes of the communiqué circulate in the feedback loop.

Keywords: comparative literature, applied graphics, comparative media studies, intermediation, hypermediation, transmediation 